\title{
Erratum to: Phase I study of lonafarnib (SCH66336) in combination with trastuzumab plus paclitaxel in Her2/neu overexpressing breast cancer: EORTC study 16023
}

Bojana Milojkovic Kerklaan • Veronique Diéras • Christophe Le Tourneau • Marja Mergui-Roelvink • Alwin D. R. Huitema · Hilde Rosing · Jos H. Beijnen · Sandrine Marreaud • Anne-Sophie Govaerts • Martine J. Piccart-Gebhart · Jan H. M. Schellens · Ahmad Awada

Published online: 18 January 2013

(c) Springer-Verlag Berlin Heidelberg 2013

Erratum to: Cancer Chemother Pharmacol (2013)

71:53-62

DOI 10.1007/s00280-012-1972-1

Unfortunately, one of the co-author's (Bojana Milojkovic Kerklaan) family name was published wrongly in the original version of the article. The correct family name is Milojkovic Kerklaan.

The online version of the original article can be found under doi:10.1007/s00280-012-1972-1.

B. Milojkovic Kerklaan · M. Mergui-Roelvink ·

J. H. M. Schellens

Department of Clinical Pharmacology, The Netherlands Cancer

Institute, Amsterdam, The Netherlands

V. Diéras · C. Le Tourneau

Department of Medical Oncology, Institute Curie, Paris, France

A. D. R. Huitema $\cdot$ H. Rosing $\cdot$ J. H. Beijnen

Department of Pharmacy and Pharmacology,

Slotervaart Hospital, Amsterdam, The Netherlands

J. H. Beijnen · J. H. M. Schellens

Department of Pharmaceutical Sciences, Science Faculty,

Utrecht University, Utrecht, The Netherlands

S. Marreaud · A.-S. Govaerts · A. Awada

NDDG/BCG Group, European Organization for Research

and Treatment of Cancer (EORTC), Brussels, Belgium

M. J. Piccart-Gebhart · A. Awada ( $\square)$

Institute Jules Bordet, Brussels, Université Libre de Bruxelles,

Brussels, Belgium

e-mail: ahmad.awada@bordet.be 